\title{
Спектры рамановского рассеяния толстых эпитаксиальных слоев GaN на SiC, полученных сублимационным сандвич-методом
}

\author{
(C) А.Н. Анисимов ${ }^{1}$, А.А. Вольфрсон ${ }^{1}$, Е.Н. Мохов 2, Ф \\ ${ }^{1}$ Физико-технический институт им. А.Ф. Иоффе Российской академии наук, \\ 194021 Санкт-Петербург, Россия \\ ${ }^{2}$ Университет ИТМО, \\ 197101 Санкт-Петербург, Россия \\ ๑ E-mail: Mokhov@mail.ioffe.ru
}

(Получена 15 февраля 2018 г. Принята к печати 22 марта 2018 г.)

Исследованы спектры рамановского рассеяния толстых ( 100 мкм и более) слоев GaN, выращенных на $\mathrm{SiC}$ кристаллах-подложках посредством сублимационного сандвич-метода. Хорошее совпадение полученных нами спектров $\mathrm{SiC}$-подложек с приводимыми в литературе свидетельствует о надежности наших измерений, а минимальные различия между нашими и литературными результатами для слоев GaN означают, что по качеству слои, выращенные нами с помощью сублимационного сандвич-метода, не уступают изготовленным методами MOVPE или CHVPE.

DOI: 10.21883/FTP.2018.09.46283.8845

\section{1. Введение}

На сегодняшний день структуры на основе нитрида галлия и его твердых растворов являются наиболее предпочтительными для создания таких высокоэффективных оптических и электрических приборов, как коротковолновые светоизлучающие диоды, лазеры, фотодетекторы, а также силовые и высоковольтные устройства. Однако выращивание слоев нитрида галлия на инородных подложках, таких как $\mathrm{SiC}, \mathrm{Al}_{2} \mathrm{O}_{3}$ и даже $\mathrm{AlN}$, который наиболее близок по своим параметрам к $\mathrm{GaN}$, приводит к появлению в слое большого количества дефектов из-за различия параметров решетки и коэффициентов термического расширения. Это вызывает значительное снижение эффективности приборов, создаваемых на основе этих слоев. Естественно, оптимальным решением было бы использование подложек, сформированных из совершенных объемных кристаллов самого $\mathrm{GaN}$. Поэтому, несмотря на значительные технологические трудности, активно развиваются и совершенствуются различные способы выращивания этих кристаллов. В их ряду одним из наиболее перспективных является сублимационный сандвич-метод (ССМ), впервые предложенный в лаборатории электроники полупроводников с большой энергией связи Физико-технического института им. А.Ф. Иоффе Российской академии наук. Первоначально этот метод использовался для выращивания кристаллов $\mathrm{SiC}[1]$, а позднее был успешно применен и для $\mathrm{GaN}$ [2]. Высокое качество получаемых этим методом толстых слоев $\mathrm{GaN}$ было подтверждено их микроскопическими, оптическими, рентгеновскими исследованиями, а также изучением электронного парамагнитного резонанса [2-5].

В данной работе с целью подтверждения высокого кристаллического совершенства слоев $\mathrm{GaN}$, полученных посредством ССМ, проведено их исследование методом рамановской спектроскопии.

\section{2. Эксперимент}

Схема установки для реализации ССМ дана на рис. 1. Подробное описание как принципов ССМ, так и деталей ростового процесса дано в работе [3]. Ростовой процесс проводился при температуре $\sim 1200^{\circ} \mathrm{C}$, зазор между $\mathrm{GaN}$-источником и $\mathrm{SiC}$-подложкой составлял 2-5 мм, а величина потока $\mathrm{NH}_{3}$ равнялась $\sim 0.5$ л/мин. Проверка качества полученных ССМ кристаллов производилась методом рамановской спектроскопии.

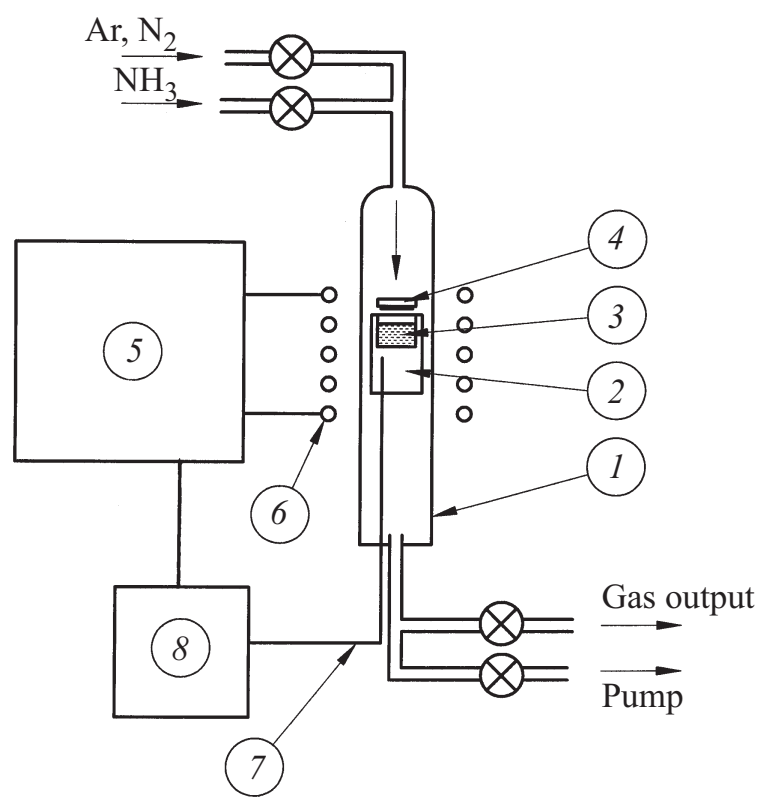

Рис. 1. Схема установки ССМ: $1-$ вертикальная кварцевая труба-реактор, 2 - графитовый нагреватель, 3 - тигель с источником (смесь $\mathrm{Ga}+\mathrm{GaN}), 4$ - держатель с закрепленной на нем подложкой $\mathrm{SiC}, 5-$ ВЧ генератор ( 440 кГц, 8 кВт), 6 - индуктор, 7 - термопара, $8-$ прибор для измерения и управления температурой. 
Измерения рамановских спектров были выполнены при комнатной температуре с помощью монохроматора фирмы Solar Instruments, оборудованного CCD камерой, позволяющей единовременно регистрировать спектр от 100 до $800 \mathrm{~cm}^{-1}$. В качестве источника возбуждения был использован $\mathrm{Nd}$ : YAG-лазер $(\lambda=532$ нм $)$. Размер лазерного пятна составлял 1 мкм, а спектральное разрешение $-2 \mathrm{~cm}^{-1}$. Мощность излучения, падающего на образец, составляла около 30 мВт. Спектры регистрировались как со стороны слоя $\mathrm{GaN}$, так и со стороны $\mathrm{SiC}-$ подложки в геометрии рассеяния назад. Для исследования использовались толстые слои $\mathrm{GaN}$, выращенные на подложках $6 \mathrm{H}$-SiC с помощью CCM. Согласно рентгеновским измерениям, полная ширина на половине высоты $(F W H M)$ линий $\omega_{\text {scan }}$ для слоев $\mathrm{GaN}$ лежала в пределах 2.5-10 угл. мин, а для кристаллов-подложек $\mathrm{SiC}$ была около 15 угл. сек.

\section{3. Результаты и их обсуждение}

На рис. 2 и 3 приведены типичные рамановские спектры, полученные в геометрии рассеяния $z(x y) \bar{z}$, для слоев $\mathrm{GaN}$, выращенных нами, и $6 H-\mathrm{SiC}$ кристаллов-подложек соответственно. Известно, что идеальные $\mathrm{GaN}$ - и $\mathrm{SiC}$-кристаллы имеют гексагональную структуру (пространственная группа симметрии $C_{6 v}^{4}$ ). Элементарная ячейка $\mathrm{GaN}$ содержат четыре атома, и, таким образом, в Г-точке оптические фононы принадлежат неприводимому представлению

$$
\Gamma_{\mathrm{opt}}=A_{1}(z)+2 B_{1}+E_{1}(x, y)+2 E_{2},
$$

где $x, y, z$ - направления поляризации. Здесь направление $z$ совпадает с направлением гексагональной оси слоя $c$, а направление $x$ перпендикулярно оси $c$ и лежит в плоскости слоя.

Элементарная ячейка $6 H-\mathrm{SiC}$ содержит 12 атомов и в Г-точке оптические фононы принадлежат непреводимому представлению [7]

$$
\Gamma_{\text {опт }}=5 A_{1}(z)+6 B_{1}+5 E_{1}(x, y)+6 E_{2} .
$$

В литературе эти фононы так же обозначаются как FTA, FLA, FTO и FLO. К раман-активным фононам принадлежат моды симетрии $A_{1}(z), E_{1}(x, y)$ и $E_{2}$, в то время

Частоты фононов $\left(\mathrm{cm}^{-1}\right)$ для $\mathrm{GaN}$ и $\mathrm{SiC}$

\begin{tabular}{c|c|c|c|c}
\hline Материал & Мода & Наш опыт & {$[6]$} & {$[7]$} \\
\hline \multirow{6}{*}{$\mathrm{GaN}$} & $E_{2}(\mathrm{low})$ & 145.3 & 144.0 & \\
& $E_{1}(\mathrm{TO})$ & 559.5 & 558.8 & \\
& $E_{2}$ (high) & 568.0 & 567.6 & \\
& $A_{1}(\mathrm{LO})$ & 733.2 & 734.0 & \\
$\mathrm{SiC}$ & FTA & $145.3,152.1$ & & 145,150 \\
& FTO & 766.6, & & $767,789,797$ \\
& & $788.1,797.3$ & & \\
& FLA & $504.5,513.6$ & & 504,514 \\
& FLO & 965.6 & & 889,965
\end{tabular}

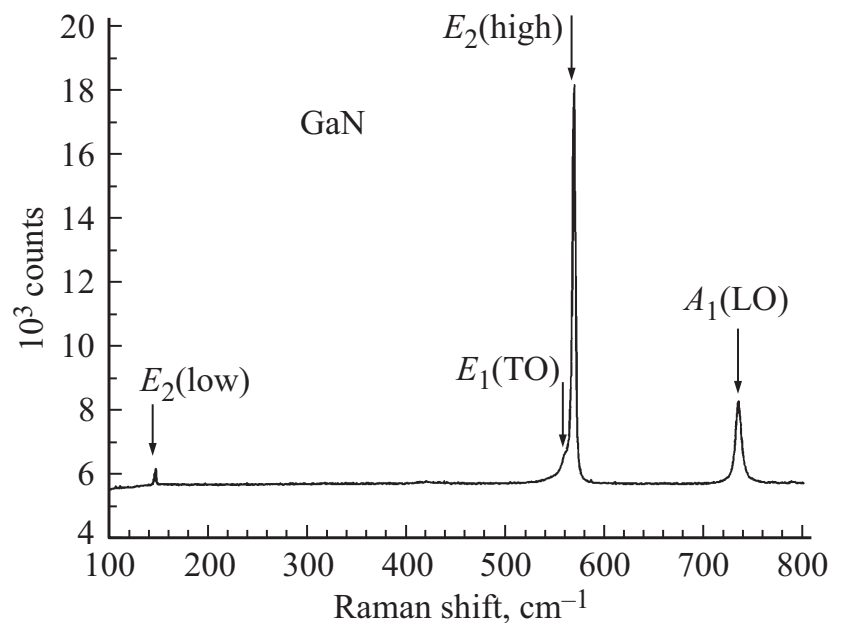

Рис. 2. Типичный рамановский спектр толстого (100 мкм и более) слоя $\mathrm{GaN}$, выращенного посредством CCM.

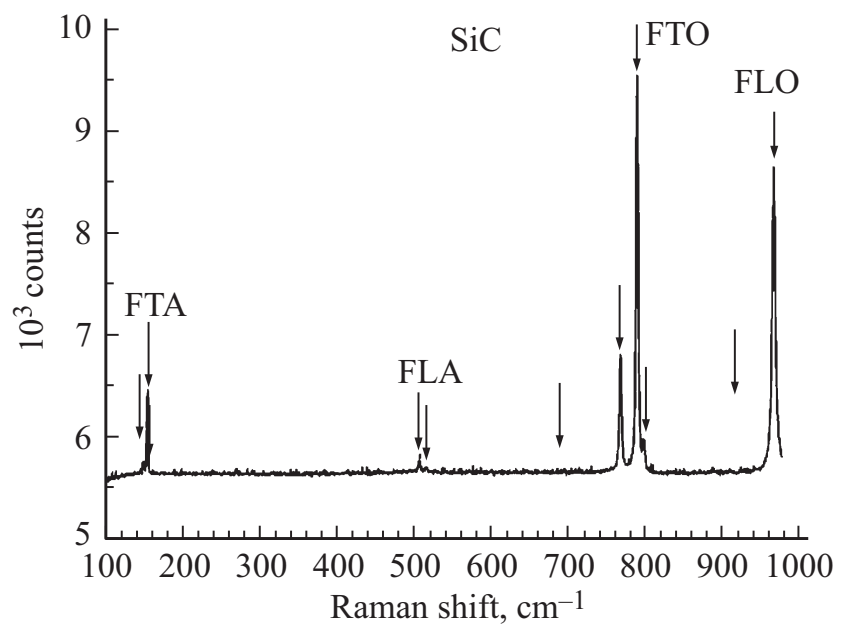

Рис. 3. Типичный рамановский спектр $\mathrm{SiC}$ кристаллаподложки.

как $B_{1}$-моды не проявляются в рамановских спектрах [6]. Моды поперечных акустических и оптических ветвей хорошо заметны. В области $150 \mathrm{~cm}^{-1}$ наблюдаются острые пики, соответствующие фононным модам симметрии $E_{2}$. $\mathrm{B} \mathrm{SiC}$ они дублетны для сложенных поперечных акустичеких мод, которые соответствуют краю базовой зоны Бриллюэна, и расщепление дублета составляет $7 \mathrm{~cm}^{-1}$, что характерно для нашей геометрии эксперимента с рассеянием назад [7]. Анализ мод $6 \mathrm{H}$-SiC показывает, что $F W H M$ линий лежит в интервале от 3 до $3.5 \mathrm{~cm}^{-1}$ для мод FTA, FTO, FLA и около $6 \mathrm{~cm}^{-1}$ для моды FLO. Для $\mathrm{GaN}$ соответственно данные параметры равны 4 и $8 \mathrm{~cm}^{-1}$. Полученные экспериментальные результаты приведены в таблице. На основании наших измерений, в сравнении с данными работ [6,7], приведенными в таблице, мы полуили хорошее совпадение экспериментальных результатов по $6 H-\mathrm{SiC}$ и $\mathrm{GaN}$. Минимальные различия в результатах для $\mathrm{GaN}$ означают, что по качеству выращенные нами с помощью ССМ слои не 
уступают изготовленным посредством методов MOVPE и CHVPE [6].

\title{
4. Заключение
}

На основании сопоставления литературных данных [6,7], линий, наблюдаемых в наших спектрах (см. таблицу), и значений их полуширины можно с большой уверенностью утверждать, что исследованные кристаллы, выращенные с помощью ССМ метода, обладают высоким совершенством кристаллической решетки, не уступающим тем, что изготовлены методами MOVPE и CHVPE [6].

\section{Список литературы}

[1] Yu.A. Vodakov, E.N. Mokhov, A.D. Roenkov. Patent of USSR N 1136501 (1983).

[2] Yu.A. Vodakov, E.N. Mokhov, A.D. Roenkov, M.E. Boiko, P.G. Baranov. J. Cryst. Growth, 183 (1/2), 10 (1997).

[3] P. Baranov, E. Mokhov, A. Ostroumov, M.G. Ramm, M.S. Ramm, V. Ratnikov, A. Roenkov, Yu. Vodakov, A. Wolfson, G. Saparin, S. Karpov, D. Zimina, Yu. Makarov, H. Juergensen. MRS Internet J. Nitride Semicond. Res., 3, 50 (1998).

[4] P.G. Baranov, I.V. Ilyin, E.N. Mokhov, A.D. Roenkov. Inst. Phys. Conf., Ser. N 155, chap. 12, 985 (1997).

[5] P.G. Baranov, I.V. Ilyin, E.N. Mokhov. Sol. St. Commun., $101(8), 611$ (1997)

[6] V.Yu. Davydov, Yu.E. Kitaev, I.N. Goncharuk, A.N. Smirnov, J. Graul, O. Semchinova, D. Uffmann, M.B. Smirnov, A.P. Mirgorodsky, R.A. Evarestov. Phys. Rev. B, 58 (19), 12899 (1998).

[7] S. Nakashima, H. Harima. Phys. Status Solidi A, 162 (1), 39 (1997).

Редактор А.Н. Смирнов

\section{Raman scattering spectra of thick GaN layers on SiC obtained by sublimation sandwich method}

\author{
A.N. Anisimov ${ }^{1}$, A.A. Wolfson ${ }^{1}$, E.N. Mokhov ${ }^{2}$ \\ ${ }^{1}$ loffe Institute, \\ 194021 St. Petersburg, Russia \\ 2 ITMO University, \\ 197101 St. Petersburg, Russia
}

Abstract Raman scattering spectra of thick $(\sim 100 \mathrm{mkm}$ and more) $\mathrm{GaN}$ layers grown on $\mathrm{SiC}$ crystal substrates by the use of sublimation sandwich method were investigated. Good agreement of $\mathrm{SiC}$ substrates spectra we got with literature sources forgives the accuracy of our measurements and quite satisfactory coincidence of our and literary results for GaN layers means that the quality of our layers is not worse than of the layers grown by MOVPE or CHVPE methods. 